\title{
Reactions of Halopyrenes with Phenyllithium in Ether
}

\author{
ARNE JENSEN and ARNE BERG \\ Department of Chemistry, University of Aarhus, Aarhus C, Denmark
}

\begin{abstract}
The four 1- and 2-fluoro- and -chloropyrenes all react with phenyllithium in ether to yield, through an aryne intermediate (1,2-pyryne), 1- and 2-phenylpyrene. Except from 2-chloropyrene these products were formed in a nearly constant ratio (about 25:75). The reactions are accelerated by piperidine. The 1- and 2-bromo- and iodopyrenes undergo halogen-metal interconversion exclusively. With lithium piperidide 1-bromopyrene gave $\mathrm{N}$-(1- and 2-pyrenyl)-piperidine in the ratio stated.
\end{abstract}

$\mathbf{T}^{2}$

he reactions of the halobenzenes and -naphthalenes with phenyllithium and lithium piperidide in ether have been systematically studied, especially by Huisgen et al., ${ }^{1}$ who have clarified the rôle of the elimination-addition mechanism in these nucleophilic substitutions.

In view of the increasing use of derivatives of polynuclear arenes in both theoretical and synthetic work we found it of interest to study, partly from a synthetic viewpoint, the reaction between the halopyrenes and phenyllithium in ether.

Whereas all of the 1-halopyrenes* have been known for years, ${ }^{2-4}$ the 2 derivatives have not been synthesized until recently. Jensen and Berg ${ }^{5}$ as well as Streitwieser, Lawler and Schwaab ${ }^{6}$ found a convenient route to 2 derivatives of pyrene in the cine-substitution, in liquid ammonia, of the bromine substituent in 1-bromopyrene by the amide ion. Thus all of the 2halopyrenes were prepared through the amine. Bolton ${ }^{7}$ recently prepared 2-chloro- and 2-bromopyrene by the more tedious route starting with the nitration of 4,5,9,10-tetrahydropyrene. Among the 4-halopyrenes only the bromocompound is known. It is not included in the present study.

\section{RESULTS AND DISCUSSION}

The eight 1- and 2-halopyrenes were reacted with phenyllithium in ether and the reaction mixture subsequently hydrolyzed or carbonized. The neutral fractions were worked up by column chromatography on alumina and were

\footnotetext{
* Ring-index numbering is used.
} 
Table 1. Reaction of halopyrenes (PyX) with phenyllithium and lithium piperidide in ether at $35^{\circ}$ with subsequent hydrolysis or carbonation. Reaction time $24 \mathrm{~h}$. If not otherwise stated 10 mmoles of PyX were used. The ratio of 3- and 4-phenylpyrene is given as percentage of their total amount (\% rel.).

\begin{tabular}{|c|c|c|c|c|c|c|c|c|c|}
\hline & \multirow{2}{*}{ PyX } & \multirow{2}{*}{$\begin{array}{c}\text { PhLi } \\
\text { mM }\end{array}$} & \multirow{2}{*}{$\begin{array}{l}\text { Piperi- } \\
\text { dine } \\
\text { mM }\end{array}$} & \multirow{2}{*}{$\begin{array}{c}\text { PyX } \\
\text { recov. } \\
\%\end{array}$} & \multicolumn{3}{|c|}{ 1- and 2-PhPy } & \multirow{2}{*}{$\begin{array}{c}\mathrm{Ph} \\
\mathrm{C}_{18} \mathrm{H}_{8} \\
\mathrm{CO}\end{array}$} & \multirow{2}{*}{$\underset{\%}{\text { PyH }}$} \\
\hline & & & & & $\begin{array}{l}1 . \\
\%\end{array}$ & $\begin{array}{l}2- \\
\%\end{array}$ & $\begin{array}{l}1-/ 2 . \\
\% \text { rel. }\end{array}$ & & \\
\hline 1 & $1-F a, b$ & 30 & - & 52 & 0 & 0 & - & 34 & 0 \\
\hline 2 & $1-F^{a}$ & 30 & - & 0 & 0 & 0.4 & - & 77 & 0 \\
\hline 3 & $1-F$ & 30 & - & 0 & 14.4 & 59.5 & $20 / 80$ & - & 0 \\
\hline 4 & $I-F^{c}$ & 30 & - & $\mathbf{5 5}$ & 5.0 & 34.2 & $13 / 87$ & - & 0 \\
\hline $\mathbf{5}$ & $1-F^{c}$ & 30 & 6 & 13.6 & 16.2 & 50.2 & $25 / 75$ & - & 0 \\
\hline 6 & $1-\mathrm{Cl}$ & 30 & - & 67 & 10.8 & trace $^{e}$ & - & - & $\mathbf{0}$ \\
\hline 7 & $1-\mathrm{Cl}^{a}$ & 30 & - & 36 & $7.9 f$ & $24.5 f$ & $24 / 76$ & 40.4 & 0 \\
\hline 8 & $1-\mathrm{Cl}$ & 30 & 6 & 0 & 19.4 & 60.8 & $24 / 76$ & - & 0 \\
\hline 9 & $1-B r$ & 30 & - & 0 & 0 & 0 & - & - & 81 \\
\hline 10 & $1-B r$ & 30 & 6 & o & 0 & 0 & - & - & 81 \\
\hline 11 & $1-\mathrm{Br}^{c}$ & 15 & 30 & 0 & $20.4^{g}$ & $54.4^{g}$ & $27 / 73$ & - & 21.3 \\
\hline 12 & $1-I^{b}$ & 17 & - & $\mathbf{0}$ & 0 & 0 & - & - & 90.6 \\
\hline 13 & $2-\mathrm{F}^{d}$ & 7.5 & - & 0 & 15.1 & 53.0 & $22 / 78$ & - & 0 \\
\hline 14 & $2-\mathrm{Cl}^{d}$ & 3.2 & - & 32 & 17.0 & 49.3 & $26 / 74$ & - & 0 \\
\hline 15 & $2-\mathrm{Cl}^{d}$ & 4.4 & 0.9 & 28.6 & 29.2 & 34.2 & $46 / 54$ & - & 0 \\
\hline 16 & 2-Bra,d & 15 & - & 0 & 0 & - & - & $69^{h}$ & 29.5 \\
\hline 17 & $2-\mathrm{I}^{d}$ & 7.5 & - & 0 & 0 & - & - & - & 93 \\
\hline 18 & $1-F^{c}$ & 48 & 40 & 0 & & & - & - & 0 \\
\hline
\end{tabular}

${ }^{a}$ Carbonation

$b$ Temp. in 1 and 12 was $0^{\circ}$ and $22^{\circ}$, respectively.

$c$ Reaction time in 4 and $5: 2 \mathrm{~h}$; in $11: 5.5 \mathrm{~h}$.

${ }^{d}$ In $13-172.27,1.05,1.48,5.0$, and 2.5 mmole, respectively, of PyX were used.

e Identified by TLC.

$f$ From decarboxylation of the phenylpyrene-carboxylic acid mixture.

$g$ Yields of $\mathrm{N}$-(1- and 2-pyrenyl)-piperidine.

$h$ Yield of 2-pyrene-carboxylic acid.

found to contain, besides unreacted starting material, if any, the isomeric 1- and 2-phenylpyrenes or pyrene. Carbonation resulted in a mixture of acids, presumably the isomeric 1-phenyl-2- and 2-phenyl-1-carboxylic acids. These mixtures were not separated, but in one experiment the acid mixture was decarboxylated to yield 1- and 2-phenylpyrene. These two compounds, the latter of which not known before, were found identical (m.p., UV, IR) with the biaryls resulting from Ullman reaction of iodobenzene with 1-iodopyrene and 2-iodopyrene, respectively. The former compound appeared, furthermore, to be identical with the 1-phenylpyrene prepared by Norman et al. ${ }^{8}$ from 1-aminopyrene.

Acta Chem. Scand. 19 (1965) No. 8 
Table 1 presents the results. The figures given for the two phenylpyrenes represent the relative amounts of these isomers in the mixture of them. Independent of the halogen and of its original site (1- or 2-position) in the pyrene molecule the ratio of the isomers (except for 15) shows a fair constancy to warrant that an aryne mechanism is operating, where a nucleophilic substitution takes place. Most of the deviations from constancy are not greater than might be expected from the preparative assay of the isomer ratio. This method of analysis was made possible by the good separability that 1-and 2-pyrene derivatives show on alumina, as already encountered for the two aminopyrenes. ${ }^{5}$ In expt. 4 with a reaction time of only $2 \mathrm{~h} 55 \%$ of the 1 -fluoropyrene was recovered. The small amounts of reaction products may account for the deviation in this instance, although fair results were obtained in expt. 13 with still smaller amounts. That the deviation in 4 does not result from a competing nucleophilic substitution without rearrangement is seen from the fact that the shift is towards the rearranged product. When 4 was repeated (expt. 5) under identical conditions except for addition of piperidine prior to the addition of the phenyllithium reagent, much better yields were obtained and another ratio resulted. This accelerating effect of piperidine (and other secondary amines) were detected by Huisgen et $a l .^{9}$ and worked out to a synthetic method for biaryls and at the same time recognized as an evidence for the aryne mechanism. In the case of 1-chloropyrene $(6,7,8)$ the same trends are encountered. 2-Chloropyrene needs further examination. It appeared not possible to determine a competition constant for 1,2-pyrene sufficiently precisely. Although phenyllithium and lithium piperidide were used in a ratio of 1:5, much favourable for addition of the piperidide, a mixture of phenylpyrenes (not separated) in a yield of $85 \%$ was the only product (18). Clearly, 1,2-pyrene, with a very high competition constant, continues the order determined by Huisgen et al. ${ }^{10}$ :

$$
\text { Benzyne }<\text { naphthyne }<\text { phenanthryne }
$$

But the supposition of Huisgen et al. that the selectivity of the aryne for the competing reagents increase with decreasing bond distance is not consistent with the high competition constant of 1,2-pyryne, as the 1,2-bond in pyrene ${ }^{11}$ with a bond distance of $1.380 \AA \pm 0.011$ is even longer than the 1,2 -bond in naphthalene.

Whereas the fluoro and chloro derivatives thus react via 1,2-pyryne (it should be noticed that the two elimination possibilities in the 2-compounds afford the same aryne), the 1-and 2-bromo and -iodo derivatives react exclusively by halogen-metal interconversion with phenyllithium. Small additions of piperidine (expt. 10) have no effect. The interconversion reaction between 1-bromopyrene and phenyllithium is much faster than the elimination reaction with lithium piperidide. But with piperidine in excess (expt. 11) the interconversion reaction is prevented as evidenced by a substantial yield $(75 \%)$ of $\mathrm{N}$-(1- and 2-pyrenyl)-piperidine in relative amounts 27.3 and $72.7 \%$ in good agreement with the value for the phenyllithium-initiated reactions. These tertiary amines were found identical (m.p., UV, IR) with the products of a usual nucleophilic reaction between 1- and 2-fluoropyrene, respectively, and piperidine in dimethyl sulfoxide, following the procedure of 
Suhr..$^{12}$ Huisgen et $a l .^{13}$ in a purely kinetic study of the reaction of aryl halides with lithium piperidide in ether concluded that 1-bromopyrene, among others, was able to react with elimination of hydrogen bromide to an aryne intermediate. The halide ions set free were determined, but no reaction products were reported.

The nucleophilic reactivity of the halogens in the 1- and 2-halopyrenes towards phenyllithium follows the same general order as that shown by the benzene and naphthalene derivatives. ${ }^{1}$

\section{EXPERIMENTAL}

Materials. The 1-halopyrenes were prepared as described in literature $\left(\mathrm{F},{ }^{4} \mathrm{Cl},{ }^{2} \mathrm{Br},{ }^{3} \mathrm{I}^{4}\right)$. All of the 2 -halopyrenes were prepared from 2-aminopyrene. ${ }^{5}$ The ethereal solution (about $1 \mathrm{M}$ ) of phenyllithium (from bromobenzene and lithium) was measured from a burette flask. It was controlled by the method of Gilman and Cartledge. ${ }^{14}$ Piperidine was distilled from potassium hydroxide and used as a $1 \mathrm{M}$ solution.

General procedure. The halopyrene $(10 \mathrm{mmoles})$ was dissolved in $200 \mathrm{ml}$ of dry ether and phenyllithium (30 mmoles) added. Reflux for $24 \mathrm{~h}$. Piperidine, if used, was added in three portions: after 0,2 , and $4 \mathrm{~h}$ (expts. 8 and 10) or after 0,20 , and $40 \mathrm{~min}$. (expt. 5). In expt. 11 half of the piperidine was added to the solution of the halopyrene and the other half was added, mixed with phenyllithium, in one half hour. In expt. 18 all of the piperidine and phenyllithium was added in admixture in one half hour. All operations were carried out in a nitrogen atmosphere.

Subsequent to hydrolysis the resulting raw material was chromatographed on alumina (Brockmann, standardized). Light petroleum (b.p. $<50^{\circ}$ ) and then cyclohexane with $10 \%$ benzene served as eluants. Fractions of $50-100 \mathrm{ml}$ were collected and the solvent was evaporated in vacuo. Unreacted halide and 1-phenylpyrene appeared first, followed by 2-phenylpyrene. The former of the two hydrocarbons needed more purification and was sublimed in vacuo. They could be crystallized from methanol and cyclohexane, respectively.

If piperidine had been present in the reaction the dried ethereal layer, before being worked up as described, was treated with dry hydrogen chloride. From the hydrochlorides precipitated the amines were set free with sodium carbonate and separated on alumina. N-(1-Pyrenyl)-piperidine was eluted with light petroleum/benzene $(3: 1)$ and the 2compound was eluted with benzene alone. They were crystallized from ethanol and cyclohexane, respectively (expt. 11).

After carbonation of a reaction mixture the ether layer was worked up as described. The water layer, after washing with ether, was chilled to $0^{\circ}$ and acidified with hydrochloric acid under vigorous stirring. The mixed acid product could be crystallized from methanol but without separation. (Found: C 84.9; H 4.44; Equiv. wt. 320.7; 323.0. Calc. for $\mathrm{C}_{23} \mathrm{H}_{14} \mathrm{O}_{2}$ : C 85.60; $\mathrm{H}$ 4.38; Equiv. wt. 322.4).

Ullmann synthesis of phenylpyrenes. With dimethylformamide present no phenylpyrenes could be isolated.

1-Phenylpyrene. 1-Iodopyrene $(1 \mathrm{~g})$ and iodobenzene $(2 \mathrm{~g})$ were heated with copper powder $(2 \mathrm{~g})$ to $200^{\circ}$ for $6 \mathrm{~h}$. After cooling was extracted with benzene. The benzene was

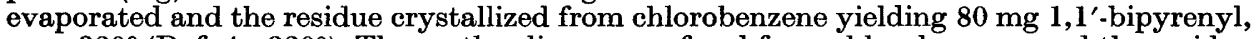
m.p. $320^{\circ}$ (Ref. $4: 320^{\circ}$ ). The mother liquor was freed from chlorobenzene and the residue subjected to fractional sublimation in vacuo to give some biphenyl and $270 \mathrm{mg}(32 \%)$

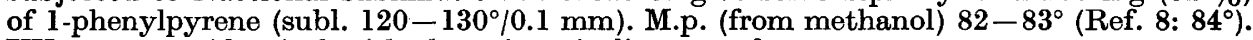
UV-spectrum identical with that given in literature. ${ }^{8}$

2-Phenylpyrene. 2-Iodopyrene $(200 \mathrm{mg})$, iodobenzene $(1 \mathrm{~g})$ and copper $(1 \mathrm{~g})$ heated to $210-220^{\circ}$ for $5 \mathrm{~h}$ gave $50 \mathrm{mg}(29.5 \%)$ of 2 -phenylpyrene, m.p. (cyclohexane) $166-167^{\circ}$. (Found: C 93.9; $\mathrm{H}$ 5.03. Calc. for $\mathrm{C}_{22} \mathrm{H}_{14}$ : C 94.93; $\mathrm{H}$ 5.07). UV: 220, 233, 274, 309.5, 322.5, and 337.5.

Preparation of $N$-pyrenyl-piperidines. The procedure of Suhr ${ }^{12}$ was followed in a modified form.

Acta Chem. Scand. 19 (1965) No. 8 
N-(1-Pyrenyl)-piperidine. 1-Fluoropyrene $(0.5 \mathrm{~g})$, piperidine $(3 \mathrm{ml})$ and dimethyl sulfoxide $(5 \mathrm{ml})$ were heated to reflux for four days. The temperature of the oilbath was slowly raised from $160^{\circ}$ to $180^{\circ}$ when the temperature of the reaction mixture raised from $123^{\circ}$ to $142^{\circ}$. The mixture was poured into water and the precipitate washed several times with water and then extracted with $10 \mathrm{ml}$ of benzene. Chromatography on alumina with light petroleum with increasing amounts of benzene yielded in several fractions $0.6 \mathrm{~g}$ $(91 \%)$ of product. UV-spectra showed that 1 -fluoropyrene was present in the front fractions only, m.p. (ethanol) $103-104^{\circ}$. (Found: C 88.6; $\mathrm{H} \mathrm{6.66;} \mathrm{N} \mathrm{4.67.} \mathrm{Calc.} \mathrm{for} \mathrm{C}_{21} \mathrm{H}_{19}$ $\mathrm{N}$ : C 88.37; H 6.71; N 4.91). UV: 212.5, 240.5, 282.5 and 355.

$N$-(2-Pyrenyl)-piperidine. 2-Fluoropyrene $(0.25 \mathrm{~g})$, piperidine $(3 \mathrm{ml})$ and dimethyl sulfoxide $(5 \mathrm{ml})$. Only the tail fractions contained pure product. Conversion of 2-fluoropyrene was about $25 \%$, m.p. (ethanol) $119-120^{\circ}$. (Found: C 87.4; H 6.62; N 5.00. Calc. for $\mathrm{C}_{21} \mathrm{H}_{19} \mathrm{~N}$ : C 88.37; $\mathrm{H} 6.71 ; \mathrm{N} \mathrm{4.91).} \mathrm{UV:} \mathrm{215,} \mathrm{282,} \mathrm{311,} \mathrm{324,} 339$.

Decarboxylation of mixed acid product from expt. 7 . The acid mixture (1.3 g) was heated with copper powder $(0.5 \mathrm{~g})$ and quinoline $(12 \mathrm{ml})$ to $240^{\circ}$ for $1.5 \mathrm{~h}$. After dilution with ether and filtering the quinoline was extracted and the ether evaporated. Chromatography, on alumina, of the residue yielded (with light petroleum) 1-phenylpyrene $(0.22 \mathrm{~g})$ and then (with light petroleum/benzene) 2-phenylpyrene $(0.68 \mathrm{~g})$.

\section{REFERENCES}

1. Huisgen, R. In Zeiss, H. Organometallic Chemistry, Chapter 2, Reinhold Publishing Co., New York 1960.

2. Vollmann, H., Becker, H., Corell, M. and Streeck, H. Ann. 531 (1937) 1.

3. Lock, G. Ber. 70 (1937) 928.

4. Lund, H. and Berg, A. Kgl. Danske Videnskab. Selskab, Mat.-Fys. Medd. 22 (1946) No. 15.

5. Jensen, A. and Berg, A. Acta Chem. Scand. 19 (1965) 520.

6. Streitwieser, A., Jr., Lawler, R. G. and Schwaab, D. J. Org. Chem. 30 (1965) 70.

7. Bolton, R. J. Chem. Soc. 19644637.

8. Norman, R. O. C., Thompson, G. A. and Waters, W. A. J. Chem. Soc. 1958175.

9. Huisgen, R., Sauer, J. and Hauser, A. Chem. Ber. 91 (1958) 23

10. Huisgen, R., Mack, W. and Möbius, L. Tetrahedron 9 (1960) 29.

11. Camerman, A. and Trotter, J. Acta Cryst. 18 (1965) 636.

12. Suhr, H. Chem. Ber. 97 (1964) 3268.

13. Huisgen, R., Mack, W., Herbig, K., Ott, N. and Anneser, E. Chem. Ber. 93 (1960) 412.

14. Gilman, H. and Cartledge, F. K. J. Organometal. Chem. 2 (1964) 447.

Received June 29, 1965. 